\title{
The 'Mozlep' System: a renewed proposal for a combined clinico-epidemiological follow-up of the leprosy patient
}

\author{
S POMIATO \\ The National Leprosy Control Programme, Ministry of Health, \\ Maputo, Mozambique
}

\section{Accepted for publication 6 November 1986}

The 'Mozlep' System originated in Mozambique (hence the name) in 1983, at the time of the start of the National Leprosy Control Programme. The aim was to implement locally the OMSLEP System, ' trying at the same time to reduce to a minimum the number of forms necessary for a correct and complete follow-up of the patient, not only on epidemiological but also on clinical grounds. The goal of the 'Mozlep' System was theref ore to supply something simple enough to fulfil the OMSLEP requirements and comprehensive enough to collect all the essential information as compactly as possible.

Apart from the inevitable administrative forms, the routine papers for the leprosy worker are basically two: The Clinical File (A Pasta) and the Clinico-epidemiological Individual Form (Ficha Individual). These are to be the subject of the present paper.

The Clinical File consists of a three-page file.* On the front page the usual headings identify the patient as a member of the community: name, surname, sex, tribe, date and place of birth and so on. At the bottom there is a section devised to follow-up the patient during his/her transfers.

At the back of the first page four anamnestic sections of records: the first for reactions and their characteristics (date, type, duration, treatment and outcome); the second for any hospitalizations, also with date, duration, diagnosis and outcome (each hospital has in addition its own recording forms); the third only for specific surgical treatments and application of prostheses; and lastly the fourth, with the date and description of up to four biopsies. Finally, on the third page there is a full description of the WHO classification of disabilities and disability grading, ${ }^{2}$ with room for up to 10 different evaluations of the hands, feet and eyes, both right and left.

The Clinico-epidemiological Individual Form (Ficha Individual) consists of a double-sided form, the front of which repeats the OMSLEP IF with only minor changes. As in the OMSLEP IF, we find three rows of boxes: the upper one for the first examination at detection, the other two, identical to each other, for the follow-ups. The numbers written on top of the boxes are exactly the same as in the OMSLEP system, so that there is no problem in filling in the Detection Form (DF) and the Annual Statistics Form (ASF).

In box no. 5 , first row, we added the age on onset, when known, for retrospective epidemiological studies. In box no. 6 , the bacteriological status was modified, replacing globi, AFB and $\mathrm{SB}$ with $\mathrm{BI}$ and MI because this is current practice in Mozambique.

* This and all the other forms referred to are in Portuguese and available from the author: Via A. Vespucci 26/3, 30173, Mestre, Venice, Italy. 
Furthermore, a 'box A' was added after box no. 9, due to the local situation: very many of the patients known at the time of the Portuguese Administration had disappeared in 1983 and it seemed wise to know, as far as possible, at the time of registration in the new National Programme, how many of the supposed 'new patients' were already included in the old one. So a square was introduced for 'old case' (caso antigo), one for their clinical status and one for the presence or absence of reactions at the moment of the second registration.

In the other two rows, boxes 13 and 23 were modified as for box no. 6; in boxes 15 and 25 the attendance for treatment was expressed in terms of percentage: less than $50 \%$, from 50 to $75 \%$, more than $75 \%$ (with the present MDT, this should be probably reformulated); and in boxes 16 and 26 the name of the leprosy reactions were introduced in detail.

Now, the new concept is that only two of these rows should be filled in, and at six-month intervals. For the new patient (i.e. first form = page no. 1, top left-hand corner) row no. 2, for instance, will remain blank whilst, for the next ones, row no. 1 will of course be left behind. The reason for that is shown on the back page of the form, which is probably the most interesting of the whole system (Figure 1).

It collects virtually all the essential clinical information of the leprosy patient. It consists of two identical halves to be also filled in at six-monthly intervals. A gap of six months was chosen because it allows us to use one form for the first semester and then a single form altogether per year. Being almost completely comprehensive, no other forms will be necessary (except that for contacts).

Each half is made of three sections. In the top section the front and the back of a human body are inscribed in a box, divided in turn into small squares, identified by numbers and capital letters, ${ }^{3}$ for statistical purposes. Here the skin lesions should be drawn. On the right side, a couple of hands and feet are depicted with some marks indicating where sensation of the palms and soles should be tested, according to the method derived from ALERT Leprosy Control Programme.

In the middle section, there is a picture of a face for the graphical recording of its lesions. On the right side are the main clinical features of a leprosy lesion, with three possible answers each arranged in such a way that tuberculoid features are towards the left, lepromatous the right.

The third section concerns the nerves. The clinical assessment for the most important of them: facial, great auricular, ulnar, median, radial, lateral-popliteal and posterior tibial, according to a number of characteristics: normal, enlarged, hard, nodular, tender, paralytic. Moreover, the presence or absence of corneal sensitivity and a simplified Voluntary Muscle Testing (VMT) are included, again according to the ALERT Leprosy Field Programme.

Lastly the Ellis test, derived from Zimbabwe; a simple test to assess the presence of a subclinical neuritis in the limbs (see Leprosy Review, 58, 00 1987).

\section{Comment}

I think there is evidence that the Mozlep System was designed to help both the clinician in the field and the epidemiologist at his desk. For the leprologist engaged in the field, in fact, it has the same function as the clinical file for the doctor in a hospital ward. Furthermore it should be valuable for the follow-up of the leprosy patient since it has been designed to record all really relevant data; it reduces to a minimum the number of documents and records; it is not in contrast with the OMSLEP System, since the same baselines are followed and the same information requested. It could however be argued that the system is not so simple as to please everybody. This may be true and it has to be recognized that its effective use calls for some kind of general as well as specific knowledge.

The Mozlep system has been devised for a leprosy supervisor, or a doctor. This does not mean that we should exclude unqualified staff from participation, but it would be unrealistic to expect from them what they have neither the knowledge nor the time to do.

Until training can be extended and improved in Mozambique for the more junior grades of leprosy worker, it is probably wise to limit the amount of information which has to be recorded and 

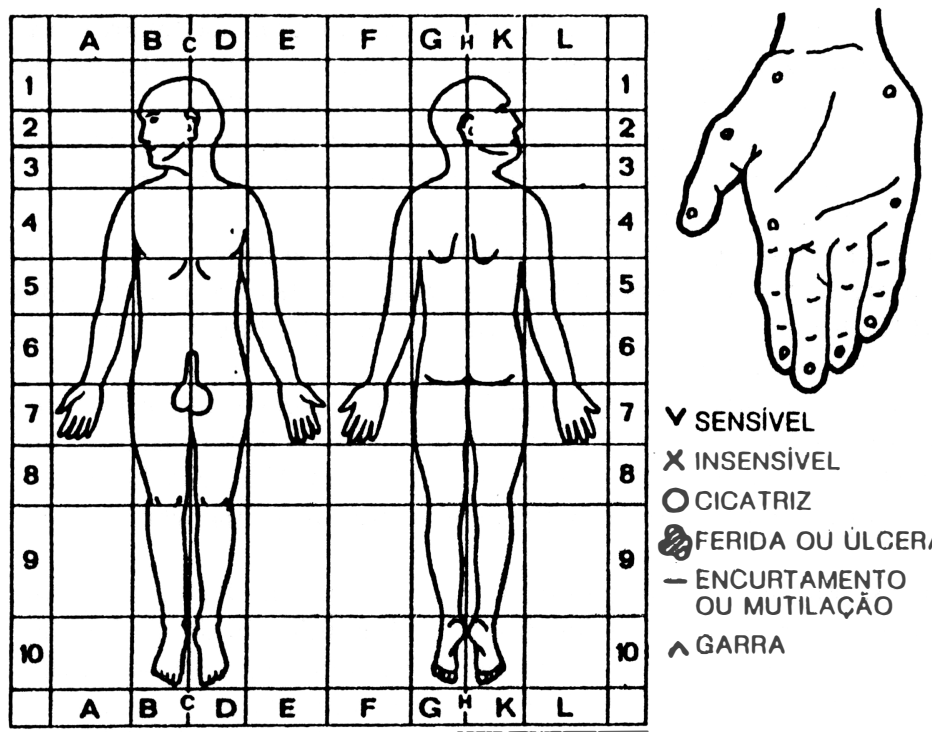

$\checkmark$ SENSIVEL

$X$ INSENSIVEL

OCICATRIZ

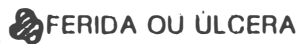

- encuRTAMENTO

OU MUTILAÇĀO

a garra
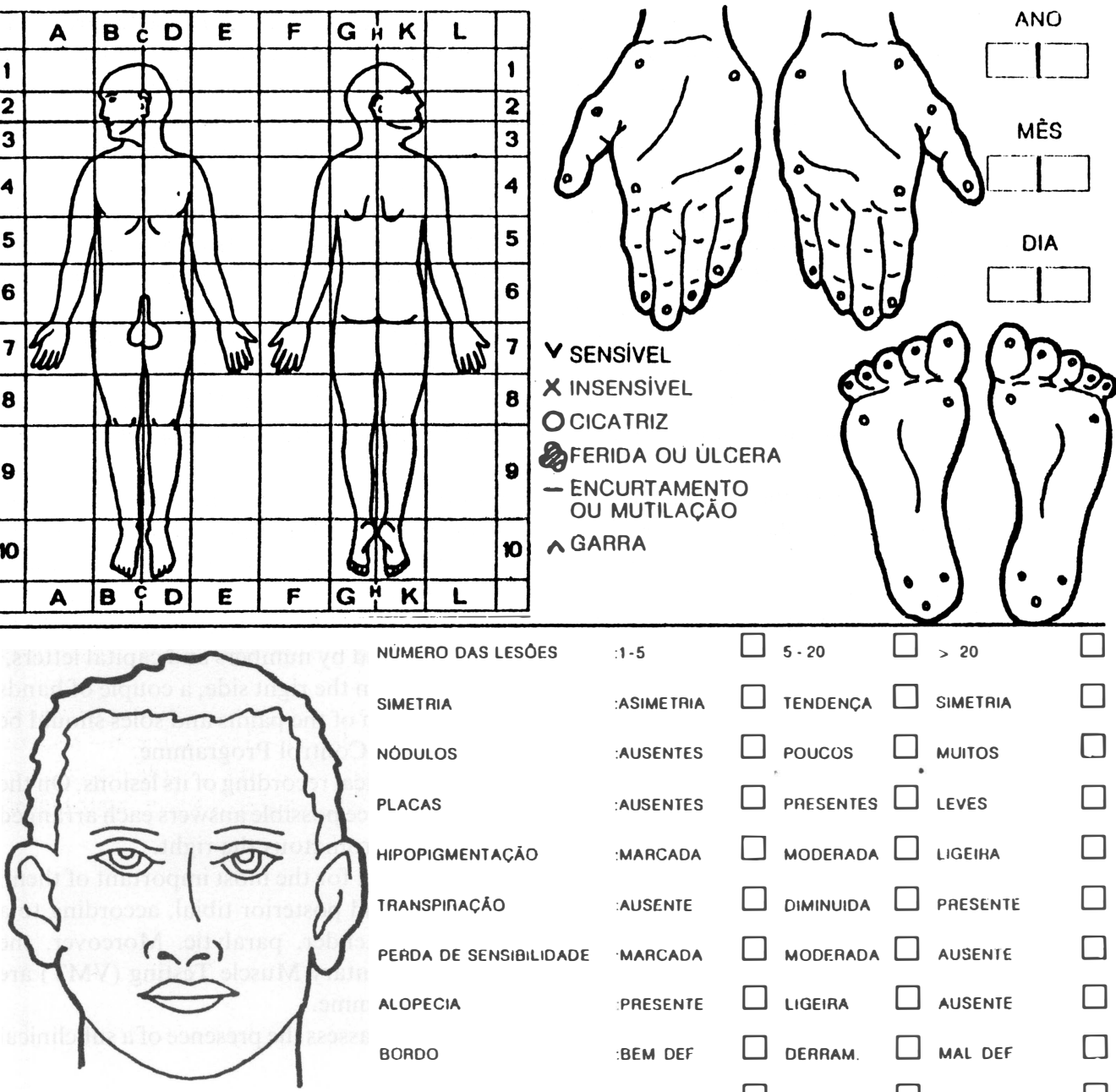

$1-5$

$\square \cdot 20$

$>20$

:Asimetria $\square$ tendençA $\square$ SIMEtria

:ausentes $\square$ poucos $\square$ muitos

:ausentes $\square$ paesentes $\square$ leves

marcada $\square$ moderada $\square$ ligeina

ausente $\square$ Diminuida $\square$ PaEsente

marcada $\square$ moderada $\square$ ausenie

presente $\square$ ligeira $\square$ ausente

bem def $\square$ derram. $\square$ mal def

MARCADA $\square$ LEVE

FUNCIONALIDADE MUSCULAR

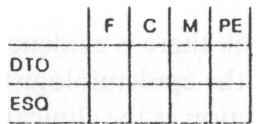

N - NORMAL F - FRACD P - PARALITICO

SENSIBILIDADE CORNEAL

ELLIS TEST

OUTRAS OBSERVAÇŌES: (TRATAMENTO, ETC.)

ASSINATURA

Figure 1. MOZLEP; form for comprehensive clinical information. (See Editor's note overleaf.) 
analysed. It is hoped that the System described here will be of practical value to the further development of the National Leprosy Control Programme.

\section{Acknowledgments}

To the Italian Leprosy Relief Association, 'Amici di Raoul Follereau', Bologna, Italy, who sponsored the work, and to the 'Studio Pubblicitario Busetto' Mestre-Venezia, Italy, who provided technical assistance with the production of the Mozlep forms.

\section{References}

${ }^{1}$ OMSLEP. Recording and reporting system for leprosy patients. Lechat MF, Misson CB, Walter J. Catholic University of Louvain, Brussels.

2 WHO. A guide to leprosy control, 1980.

3 Boerrigter, G. Grid system and body diagram for leprosy. Lepr Rev, 1983; 54: 115.

Editor's note. The author kindly supplied all the forms referred to in the text, but, partly because of shortage of space and partly because they are in Portuguese, we print only the above, which is the most important.

Note that Figure 1 is one half of the entire form (the left half). The entire form has a duplicate right half. Reading from above downwards, the words under the hands mean-sensitive, insensitive, scar, wound or ulcer, shortening or mutilation and clawing. In the middle section, the titles from above downwards mean - number of lesions, symmetry, nodules, plaques, hypopigmentation, sweating, loss of sensation, hair loss, border, central healing. 